\title{
Complement-4 Deficiency in a Child with Systemic Lupus Erythematosus Presenting with Standard Treatment-Resistant Severe Skin Lesion
}

\author{
Betul Sozeri, ${ }^{1}$ Sevgi Mir, ${ }^{2}$ and Afig Berdeli ${ }^{3}$ \\ ${ }^{1}$ Department of Pediatric Rheumatology, Faculty of Medicine, Ege University, Bornova, 35040 Izmir, Turkey \\ ${ }^{2}$ Department of Pediatric Nephrology, Faculty of Medicine, Ege University, Bornova, 35040 Izmir, Turkey \\ ${ }^{3}$ Department of Molecular Medicine, Faculty of Medicine, Ege University, Bornova, 35040 Izmir, Turkey
}

Correspondence should be addressed to Betul Sozeri, betulsozeri@yahoo.com

Received 4 December 2010; Accepted 10 January 2011

Academic Editor: M. Goto

Copyright () 2011 Betul Sozeri et al. This is an open access article distributed under the Creative Commons Attribution License, which permits unrestricted use, distribution, and reproduction in any medium, provided the original work is properly cited.

\begin{abstract}
The complement system is of great importance in systemic lupus erythematosus. Complete genetically determined deficiencies are with few exceptions reported for the various complement proteins, and most of the deficiency states are rare. Deficiencies of the factors in the classical pathway are also associated with development SLE and SLE-like disorders. Most of the patients with lupus present skin involvement. Approximately, 75-95\% of patients with cutaneous lupus erythematosus respond to antimalarial therapy and/or topical glucocorticosteroids. Immunosuppressive agents are usually considered a second-line approach in patients with resistant disease. In this study, we present the clinical features and determine the molecular basis responsible for the complete $\mathrm{C} 4 \mathrm{~A}$ and $\mathrm{C} 4 \mathrm{~B}$ deficiencies in a lupus patient presented subacute cutaneous lupus erythematosus and resistance to treatment.
\end{abstract}

\section{Introduction}

Lupus erythematosus is a chronic, autoimmune disease resulting from an interaction of genetic, environmental, and hormonal factors and characterized by a spectrum of clinical forms with a variable evaluation from a localized cutaneous form to life-threatening systemic form. Skin involvement occurs in $70-85 \%$ of all patients with lupus [1]. Specific skin lesions of cutaneous lupus erythematosus are classified as acute cutaneous lupus erythematosus, subacute cutaneous lupus erythematosus (SCLE), and chronic cutaneous lupus erythematosus, according to the clinical characteristics of the lesions [1].

Subacute cutaneous lupus erythematosus (SCLE) may present with annular or papulosquamous cutaneous lesions that are symmetrically located in the sun-exposed areas of the body [2]. SCLE shows typical serological findings, with anti-Ro (SS-A) antibodies present in up to $100 \%$ of patients $[3,4]$. However, antinuclear antibodies (ANAs), complement C3/C4 deficiency, rheumatoid factor, circulating immune complexes, lymphopenia, and thrombocytopenia can frequently be detected. Severe neurological or nephrological involvement is rare in SCLE, whereas mild musculoskeletal involvement is commonly observed. It is well known that some patients suffering from CLE develop extracutaneous manifestations during the course of their disease; up to $30 \%$ of patients with SCLE show systemic involvement [5]. Most patients with SCLE can be sufficiently treated with photo protection, topical corticosteroids, antimalarials, or a combination of these. When standard therapy fails, secondline agents approach [6].

The complement system is a group of plasma and membrane proteins that are sequentially activated via proteolytic cleavages to defend against microbial infections $[7,8]$.

The complement system is of great importance in systemic lupus erythematosus (SLE). Complement contributes to inflammation and tissue damage in this disease, but seemingly in paradox, deficiency of some complement proteins dramatically increases the risk for SLE [9]. Deficiency states within the classical pathway are associated with increased risk to develop SLE and SLE-like disease [10].

Genetically determined complement deficiencies are inborn errors and may have an impact on the development 


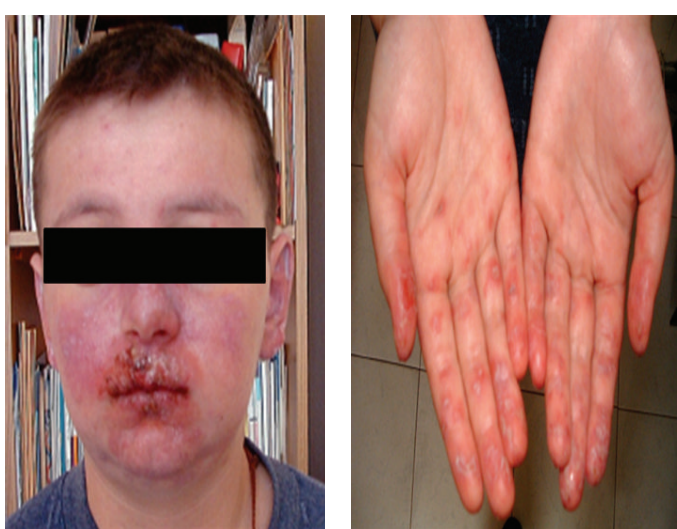

(a)

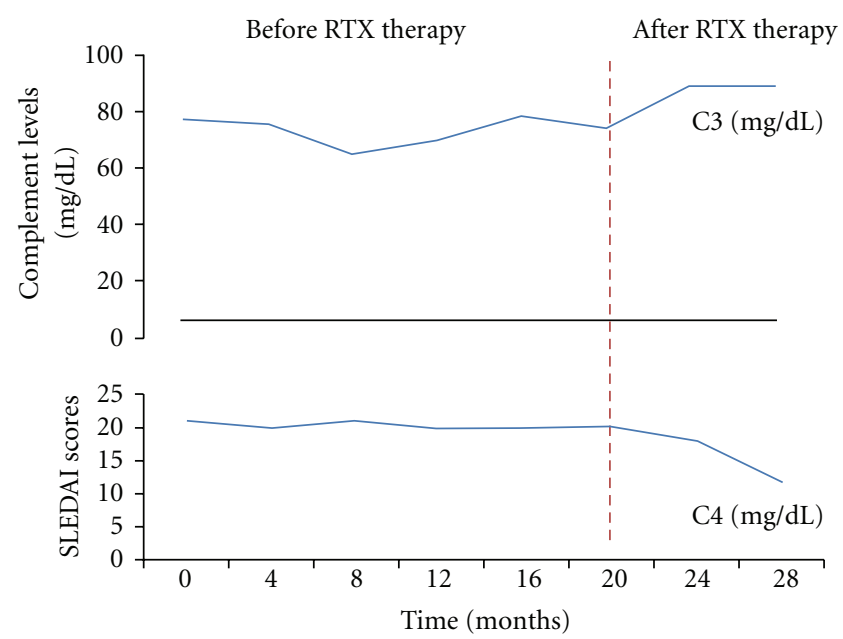

(b)

FIGURE 1: (a) Skin lesions of the patient showing on face and fingers. (b) Serum complement C3 levels and SLEDAI scores before rituximab therapy and at the end of the followup period.

of the immune system. Classical pathway deficiency has led to different hypothesis to explain roles for complement in SLE pathogenesis [9]. Complement deficiency leads to impaired handling of immune complex and inadequate clearance apoptotic cell debris [11, 12]. Another hypothesis suggests that the complement system has an important role in the development of tolerance against self [13]. Also, complement deficiency results in lack of normal B-cell tolerance and provides production of autoantibodies [9]. In addition, complement components are in some ways also important for regulation of cytokine production, especially Type 1 interferons have been shown to have a central role in the pathogenesis of SLE $[14,15]$.

While the genetic basis for a majority of SLE cases is polygenic, a homozygous deficiency in one of the early complement components alone can be strong enough to cause the disease, a situation similar to a single gene defect in an autosomal recessive disease $[16,17]$. Respectively, 93\% and $78 \%$ of patients with complete $\mathrm{C} 1 \mathrm{q}$ and $\mathrm{C} 4$ deficiencies eventually develop SLE or a lupus-like disease [18].

Genetically, the complement $C 4$ gene located in the class III region of the major histocompatibility complex (MHC) on chromosome 6p21.3. About 40 protein variants for complement C4 have been documented [19]. These proteins are segregated into two classes, the acidic $\mathrm{C} 4 \mathrm{~A}$ and the basic $\mathrm{C} 4 \mathrm{~B}$. Each $\mathrm{C} 4$ gene either codes for a $\mathrm{C} 4 \mathrm{~A}$ or a $\mathrm{C} 4 \mathrm{~B}$ protein [20]. C4A is believed to be important in the clearances of immune complexes, and $\mathrm{C} 4 \mathrm{~B}$ is more powerful in propagating the complement activation cascades. The complete absence of both $\mathrm{C} 4 \mathrm{~A}$ and $\mathrm{C} 4 \mathrm{~B}$ proteins may therefore lead to decreased ability of immune defense against microbes as well as inefficient disposal of immune complexes.

To date, 28 individuals with complete $C 4$ deficiency from 19 families have been reported [21, 22]. Among them, 15 individuals developed SLE, 7 developed lupus-like diseases, and four of the remaining subjects were only inflicted by kidney diseases [23].
In this study, we present the clinical features and determine the molecular basis responsible for the complete $\mathrm{C} 4 \mathrm{~A}$ and $\mathrm{C} 4 \mathrm{~B}$ deficiencies in a lupus patient presented with subacute cutaneous lupus erythematosus and progression systemic form and resistance to treatment.

\section{Case Report}

Seventeen-year-old patient was a male born by parents of non consanguineous marriage. He was diagnosed with SCLE at the age of 15 years old and had local therapy in dermatology clinic before admitting our clinic. Family history for rheumatologic disease was negative. On physical examination, his temperature 38.3 , respiratory rate $38 / \mathrm{min}$, pulse rate $100 / \mathrm{min}$, and blood pressure was found as 90/70 $\mathrm{mmHg}$. In auscultation, lungs were clear and the heart sounds were normal. Abdominal palpation was normal. His clinical presentation included severe malar rash with marked photosensitivity and bullous lesions on the tips of fingers and hands (Figure 1). Skin biopsy was performed. There was interface dermatitis with irregularityv and loss of basal cells. In the papillary and upper reticular dermis was a perivascular and interstitial lymphocytic infiltrate. There was granular deposition of Ig A, IgM, and C3 at the dermal-epidermal junction. Also he has arthritis which described swelling, tenderness, and pain on all small joints.

Laboratory tests showed an erythrocyte sedimentation rate (ESR) of $100 \mathrm{~mm} / \mathrm{h}, \mathrm{C}$-reactive protein of $<0.3 \mathrm{mg} / \mathrm{dL}$ (normal), hemoglobin of $11.1 \mathrm{~g} / \mathrm{dL}$, hematocrit of $31 \%$, white blood cell count (WBC) of $4900 / \mathrm{mm}^{3}$ with normal differential count, platelet count of $197000 / \mathrm{mm}^{3}$, serum urea of $25 \mathrm{mg} / \mathrm{dL}$, serum creatinine of $0.8 \mathrm{mg} / \mathrm{dL}$, albumine of $3.5 \mathrm{~g} / \mathrm{dL}$, total cholesterol of $106 \mathrm{mg} / \mathrm{dL}$, triglycerides of $57 \mathrm{mg} / \mathrm{dL}$, calcium of $8.7 \mathrm{mg} / \mathrm{dL}$, sodium of $140 \mathrm{mEq} / \mathrm{L}$, potasium of $4.7 \mathrm{mEq} / \mathrm{L}$, chloride of $107 \mathrm{mEq} / \mathrm{L}$, alanine aminotransferase of $23 \mathrm{U} / \mathrm{L}$, and aspartate aminotransferase of 
TABLE 1: The results of complement gene analysis.

\begin{tabular}{lccccc}
\hline Exon & $\begin{array}{c}\text { C4A gene } \\
\text { Aminoacid mutation }\end{array}$ & State & Exon & $\begin{array}{c}\text { C4B gene } \\
\text { Aminoacid mutation }\end{array}$ & State \\
\hline 9 & S374Y & $\mathrm{h}$ & 26 & L1120P & $\mathrm{h}$ \\
23 & E959D & $\mathrm{h}$ & 26 & S1121C & $\mathrm{h}$ \\
24 & L986L & $\mathrm{h}$ & 26 & $\mathrm{I} 1124 \mathrm{~L}$ & $\mathrm{~h}$ \\
28 & $\mathrm{D} 1176 \mathrm{~S}$ & $\mathrm{~h}$ & 26 & $\mathrm{H} 1125 \mathrm{D}$ & $\mathrm{h}$ \\
28 & $\mathrm{~A} 1205 \mathrm{~A}$ & $\mathrm{~h}$ & 28 & $\mathrm{~A} 1205 \mathrm{~A}$ & $\mathrm{~h}$ \\
28 & $\mathrm{~V} 1207 \mathrm{~A}$ & $\mathrm{~h}$ & 28 & $\mathrm{~V} 1207 \mathrm{~A}$ & $\mathrm{~h}$ \\
28 & $\mathrm{~L} 1210 \mathrm{~A}$ & $\mathrm{~h}$ & 28 & L1210A & $\mathrm{h}$ \\
10. Intron & $+19 \mathrm{G}>\mathrm{C}$ & $\mathrm{h}$ & 19. Intron & $+33 \mathrm{C}>\mathrm{T}$ & $\mathrm{H}$ \\
12. Intron & $+23 \mathrm{C}>\mathrm{A}$ & $\mathrm{h}$ & 20. Intron & $+7 \mathrm{G}>\mathrm{A}$ & $\mathrm{H}$ \\
\hline
\end{tabular}

h: Heterozygote, H: Homozygote.

$16 \mathrm{U} / \mathrm{L}$. He had positivity for antinuclear antibody (1/1280), positivity for anti-Ro/SSA antibodies and negative ds DNA. Prior laboratory measurements showed no detectable $\mathrm{C} 4$ proteins, serum C3 levels were lower $(77 \mathrm{mg} / \mathrm{dL})$ and $\mathrm{C} 1 \mathrm{q}$ inhibitor levels were normal. He had renal involvement including moderate proteinuria. Kidney biopsies confirmed the presence of mesengioprolipherative glomerulonephritis. Immunofluorescence experiments showed mesangial deposits of IgG,C3 (+++), IgA (+++) and C1q $(+)$.

After he was diagnosed as SLE according to American college of Rheumatology (ACR) criteria, high-ose "pulse" therapy was performed with methylprednisolone $(30 \mathrm{mg} / \mathrm{kg} /$ day for 3 days), followed by prednisone ( $2 \mathrm{mg} / \mathrm{kg} /$ day), Hydroxychloroquine $(5 \mathrm{mg} / \mathrm{kg} /$ day), and topical therapy. He started Cyclophosphamide pulse therapy $\left(500 \mathrm{mg} / \mathrm{m}^{2}\right)$ because his complains were not resolved. After from second dose of cyclophosphamide $\left(750 \mathrm{mg} / \mathrm{m}^{2}\right)$, he had urticarial lesions and stopped this therapy. He started Mycophenolate sodium ( $720 \mathrm{mg} /$ day). In spite of these medications, his skin lesions, arthritis were persisted; in addition, myalgia and fatigue appeared. He received rituximab infusions at a dose of 1 gram at days 1 and 15 . He was premedicated with chlorpheniramine and acetaminophen 1 hour prior to the rituximab infusion. In addition, a 100-mg dose of intravenous methylprednisolone was given immediately prior to the rituximab infusion. After rituximab therapy was administered, oral low dose prednisolone $(0,5 \mathrm{mg} / \mathrm{kg} 7$ day $)$ and Mycophenolate sodium were continued.

His complaints and laboratory values and SLEDAI scores were improved significantly after rituximab treatment, as shown in Figure 1(b). Repeated laboratory measurements showed no detectable C4 proteins, but serum C3 levels were normal.

We performed both $\mathrm{C} 4$ gene mutation analyses. His sample was kept in sterile EDTA bottle and stored at $-80^{\circ} \mathrm{C}$. Genomic DNA extraction was carried out using the standard phenol/chloroform method. After PCR amplification with intron-exon binding primers, mutation was detected by direct DNA sequencing method. These results were showed in Table 1.

\section{Discussion}

We report a child with SLE and C4 deficiency and with severe skin involvement that proved to be subacute cutaneous lupus erythematosus (SCLE). In our patient, the diagnosis of SLE was based on the presence of constitutional symptoms, malar rash, photosensitivity, oral ulceration, arthritis, anemia, a high titer of ANA, and low C3, C4. The patient resistant to initial therapies including HQK, Prednisolon and CYC.

Rituximab is a chimeric monoclonal IgGlantibody that binds specifically to the CD20 antigen and mediates Bcell lysis. Prior studies have shown that rituximab therapy can be a safe and efficacious addition to therapy with standard immunosuppressive agents in patients with refractory childhood SLE [24-29]. In our case, Rituximab led to a remarkable improvement of skin lesions, resulting in a significant decrease of the SLEDAI from 20 at the beginning to 5 at the end of therapy. In addition, he exhibited a low C4 level during the extended period of observation. Finally, the genetic phenotyping of complement revealed that he was homozygous for C4B deficiency.

SLE is a systemic autoimmune disease characterized by the breakdown of immunotolerance and the production of a wide range of autoantibodies that target multiple tissues and organs [30]. Homozygous complement deficiencies represent rare conditions. These are estimated to be found in less than $1 \%$ of SLE patients $[31,32]$. Respectively, $93 \%$ and $78 \%$ of patients with complete $\mathrm{Clq}$ and $\mathrm{C} 4$ deficiencies eventually develop SLE or a lupus-like disease $[22,33]$. In addition, the concordance rates for siblings with homozygous deficiency of C1q or C4 to develop SLE are 90\% and $80 \%$, respectively, which are even higher than the rate in monozygotic twins (26-60\%) with other genetic defects [17].

C4A deficiency causes autoimmune disease, especially systemic lupus erythematosus [34]. Indeed, approximately $15 \%$ of Caucasian SLE patients exhibit homozygous C4A deficiency, whilst more than $50 \%$ of Caucasian patients with SLE have heterozygous C4A deficiency [35]. C4B deficiency caused autoimmune-associated diseases, such as systemic lupus erythematosus, or diseases with an autoimmune component, such as autism $[36,37]$. 
Heterozygous and homozygous deficiencies of C4A were present in $40-60 \%$ of SLE patients from almost all ethnic groups such as Northern and Central Europeans, AngloSaxons, Caucasians in the US, African Americans, Asian Chinese, Koreans, and Japanese [38]. The major causes for C4AQ0 in Caucasian and African SLE patients are the presence of a mono-S RCCX module with a single, short $\mathrm{C} 4 \mathrm{~B}$ gene and the 2-bp insertion into the sequence for codon 1213 at exon 29 of the mutant C4A gene [39]. We found heterozygous genetic deficiency of $\mathrm{C} 4 \mathrm{~A}$ gene, also heterozygous and homozygous deficiencies of $\mathrm{C} 4 \mathrm{~B}$ in our patient.

In conclusion, we report a case of C4B deficiency accompanied with SLE with therapy-resistant skin involvement. Further studies are needed to clarify the relationship of C4B deficiency and SLE which presented severe skin involvement.

\section{Conflict of Interests}

The authors declare no conflict of interests.

\section{References}

[1] J. N. Gilliam and R. D. Sontheimer, "Distinctive cutaneous subsets in the spectrum of lupus erythematosus," Journal of the American Academy of Dermatology, vol. 4, no. 4, pp. 471-475, 1981.

[2] R. D. Sontheimer, J. R. Thomas, and J. N. Gilliam, "Subacute cutaneous lupus erythematosus. A cutaneous marker for a distinct lupus erythematosus subset," Archives of Dermatology, vol. 115, no. 12, pp. 1409-1415, 1979.

[3] R. D. Sontheimer, P. J. Maddison, M. Reichlin, R. E. Jordon, P. Stastny, and J. N. Gilliam, "Serologic and HLA associations in subacute cutaneous lupus erythematosus, a clinical subset of lupus erythematosus," Annals of Internal Medicine, vol. 97, no. 5, pp. 664-671, 1982.

[4] L. A. Lee, K. Alvarez, T. Gross, and J. B. Harley, "The recognition of human $60-\mathrm{kDa}$ Ro ribonucleoprotein particles by antibodies associated with cutaneaus lupus and neonatal lupus," Journal of Investigative Dermatology, vol. 107, no. 2, pp. 225-228, 1996.

[5] E. Chlebus, H. Wolska, M. Blaszczyk, and S. Jablonska, "Subacute cutaneous lupus erythematosus versus systemic lupus erythematosus: diagnostic criteria and therapeutic implications," Journal of the American Academy of Dermatology, vol. 38, no. 3, pp. 405-412, 1998.

[6] B. B. Furner, "Treatment of subacute cutaneous lupus erythematosus," International Journal of Dermatology, vol. 29, no. 8, pp. 542-547, 1990.

[7] M. J. Walport, "Advances in immunology: complement (first of two parts)," New England Journal of Medicine, vol. 344, no. 14, pp. 1058-1066, 2001.

[8] K. B. Reid and R. R. Porter, "The proteolytic activation systems of complement," Annual Review of Biochemistry, vol. 50, pp. 433-464, 1981.

[9] L. Truedsson, A. A. Bengtsson, and G. Sturfelt, "Complement deficiencies and systemic lupus erythematosus," Autoimmunity, vol. 40, no. 8, pp. 560-566, 2007.

[10] A. P. Manderson, M. Botto, and M. J. Walport, "The role of complement in the development of systemic lupus erythematosus," Annual Review of Immunology, vol. 22, pp. 431-456, 2004.

[11] K. A. Davies, A. M. Peters, H. L. C. Beynon, and M. J. Walport, "Immune complex processing in patients with systemic lupus erythematosus. In vivo imaging and clearance studies," Journal of Clinical Investigation, vol. 90, no. 5, pp. 2075-2083, 1992.

[12] P. R. Taylor, A. Carugati, V. A. Fadok et al., "A hierarchical role for classical pathway complement proteins in the clearance of apoptotic cells in vivo," Journal of Experimental Medicine, vol. 192, no. 3, pp. 359-366, 2000.

[13] M. C. Carroll, "The role of complement in B cell activation and tolerance," Advances in Immunology, no. 74, pp. 61-88, 2000.

[14] L. Ronnblom, M. L. Eloranta, and G. V. Alm, "Role of natural interferon- $\alpha$ producing cells (plasmacytoid dendritic cells) in autoimmunity," Autoimmunity, vol. 36, no. 8, pp. 463-472, 2003.

[15] V. Pascual, L. Farkas, and J. Banchereau, "Systemic lupus erythematosus: all roads lead to type I interferons," Current Opinion in Immunology, vol. 18, no. 6, pp. 676-682, 2006.

[16] B. P. Tsao and H. Wu, "The genetics of human lupus," in Dubois' Lupus Erythematosus, L. C. Wallace and B. H. Hahn, Eds., pp. 54-81, Lippincott Williams \& Wilkins, Philadeiphia, Pa, USA, 7th edition, 2008.

[17] T. J. Vyse and B. L. Kotzin, "Genetic susceptibility to systemic lupus erythematosus," Annual Review of Immunology, vol. 16, pp. 261-292, 1998.

[18] Y. L. Wu, G. Hauptmann, M. Viguier, and C. Y. Yu, "Molecular basis of complete complement C4 deficiency in two NorthAfrican families with systemic lupus erythematosus," Genes and Immunity, vol. 10, no. 5, pp. 433-445, 2009.

[19] G. Mauff, B. Luther, P. M. Schneider et al., "Reference typing report for complement component C4," Experimental and Clinical Immunogenetics, vol. 15, no. 4, pp. 249-260, 1998.

[20] C. Y. Yu, E. K. Chung, Y. Yang et al., "Dancing with complement C4 and the RP-C4-CYP21-TNX (RCCX) modules of the major histocompatibility complex," Progress in Nucleic Acid Research and Molecular Biology, vol. 75, pp. 217-292, 2003.

[21] G. Hauptmann, G. Tappeiner, and J. A. Schifferli, in Inherited Deficiency of the Fourth Component of Human Complement, F. S. Rosen and M. Seligmann, Eds., pp. 253-266, Hardwood Academic Publishers, 1993.

[22] C. Y. Yu, G. Hauptmann, Y. Yang et al., "Complement deficiencies in human systemic lupus erythematosus (SLE) and SLE nephritis: epidemiology and pathogenesis," in Systemic Lupus Erythematosus: A Companion to Rheumatology, G. C. Tsokos, Ed., pp. 203-213, Elsevier, Philadelphia, Pa, USA, 2007.

[23] Y. Yang, E. K. Chung, B. Zhou et al., "The intricate role of complement component C4 in human systemic lupus erythematosus," Current Directions in Autoimmunity, vol. 7, pp. 98-132, 2004.

[24] A. Thatayatikom and A. J. White, "Rituximab: a promising therapy in systemic lupus erythematosus," Autoimmunity Reviews, vol. 5, no. 1, pp. 18-24, 2006.

[25] S. D. Marks and K. Tullus, "Targeted B-cell depletion therapy in childhood-onset systemic lupus erythematosus: progress to date," Pediatric Drugs, vol. 9, no. 6, pp. 371-378, 2007.

[26] S. D. Marks, S. Patey, P. A. Brogan et al., "B lymphocyte depletion therapy in children with refractory systemic lupus erythematosus," Arthritis and Rheumatism, vol. 52, no. 10, pp. 3168-3174, 2005.

[27] M. El-Hallak, B. A. Binstadt, A. M. Leichtner et al., "Clinical effects and safety of rituximab for treatment of refractory 
pediatric autoimmune diseases," Journal of Pediatrics, vol. 150, no. 4, pp. 376-382, 2007.

[28] O. Nwobi, C. L. Abitbol, J. Chandar, W. Seeherunvong, and G. Zilleruelo, "Rituximab therapy for juvenile-onset systemic lupus erythematosus," Pediatric Nephrology, vol. 23, no. 3, pp. 413-419, 2008.

[29] M. Willems, E. Haddad, P. Niaudet et al., "Rituximab therapy for childhood-onset systemic lupus erythematosus," Journal of Pediatrics, vol. 148, no. 5, pp. 623.e3-627.e3, 2006.

[30] D. J. Wallace and B. H. Hahn, Dubios' Lupus Erythematosus, Lippincott Williams \& Wilkins, Philadelphia, Pa, USA, 7th edition, 2007.

[31] J. S. Navratil, L. C. Korb, and J. M. Ahearn, "Systemic lupus erythematosus and complement deficiency: clues to a novel role for the classical complement pathway in the maintenance of immune tolerance," Immunopharmacology, vol. 42, no. 1-3, pp. 47-52, 1999.

[32] M. C. Pickering, M. Botto, P. R. Taylor, P. J. Lachmann, and M. J. Walport, "Systemic lupus erythematosus, complement deficiency, and apoptosis," Advances in Immunology, vol. 76, pp. 227-324, 2000

[33] A. P. Manderson, M. Botto, and M. J. Walport, "The role of complement in the development of systemic lupus erythematosus," Annual Review of Immunology, vol. 22, pp. 431-456, 2004.

[34] A. G. Sjöholm, G. Jönsson, J. H. Braconier, G. Sturfelt, and L. Truedsson, "Complement deficiency and disease: an update," Molecular Immunology, vol. 43, no. 1-2, pp. 78-85, 2006.

[35] K. H. Traustadottir, A. Sigfusson, K. Steinsson, and K. Erlendsson, "C4A deficiency and elevated level of immune complexes: the mechanism behind increased susceptibility to systemic lupus erythematosus," Journal of Rheumatology, vol. 29, no. 11, pp. 2359-2366, 2002.

[36] M. L. Lokki, A. Circolo, P. Ahokas, K. L. Rupert, C. Y. Yu, and H. R. Colten, "Deficiency of human complement protein $\mathrm{C} 4$ due to identical frameshift mutations in the C4A and C4B genes," Journal of Immunology, vol. 162, no. 6, pp. 3687-3693, 1999.

[37] E. S. Samano, L. M. Ribeiro, R. G. Gorescu, K. C. Rocha, and A. S. Grumach, "Involvement of C4 allotypes in the pathogenesis of human diseases," Revista do Hospital das Clinicas, vol. 59, no. 3, pp. 138-144, 2004.

[38] W. Ittiprasert, S. Kantachuvesiri, K. Pavasuthipaisit et al., "Complete deficiencies of complement C4A and C4B including 2-bp insertion in codon 1213 are genetic risk factors of systemic lupus erythematosus in Thai populations," Journal of Autoimmunity, vol. 25, no. 1, pp. 77-84, 2005.

[39] P. Cornillet, J. L. Pennaforte, F. Philbert et al., "Complement C4A gene deletion in patients with systemic lupus erythematosus in France," Journal of Rheumatology, vol. 20, no. 9, pp. 1633-1634, 1993. 


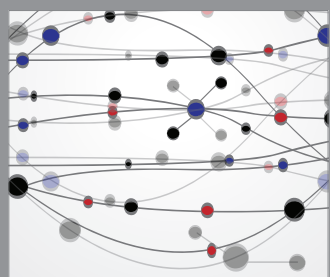

The Scientific World Journal
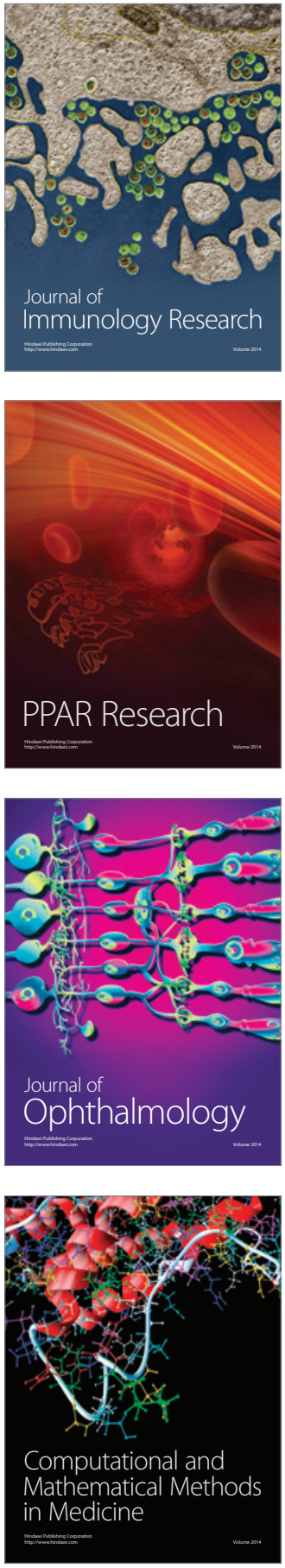

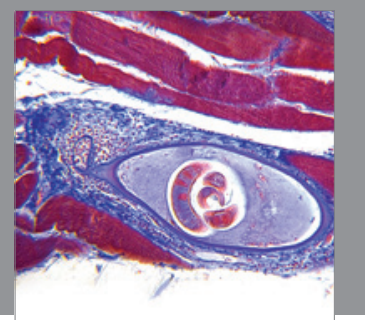

Gastroenterology

Research and Practice
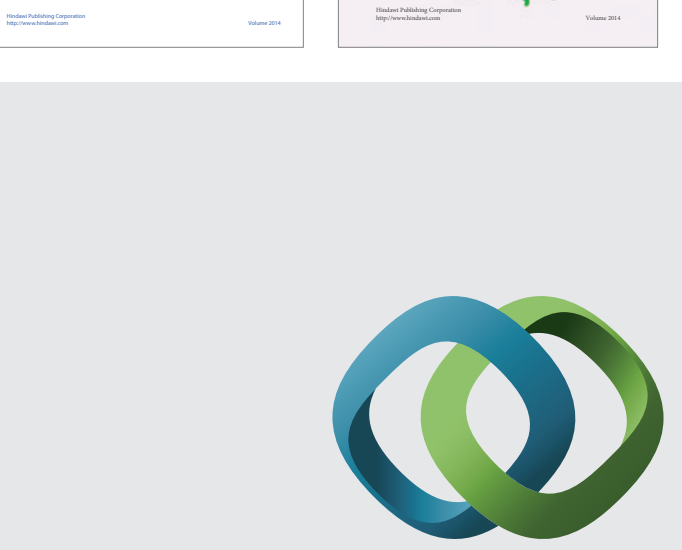

\section{Hindawi}

Submit your manuscripts at

http://www.hindawi.com
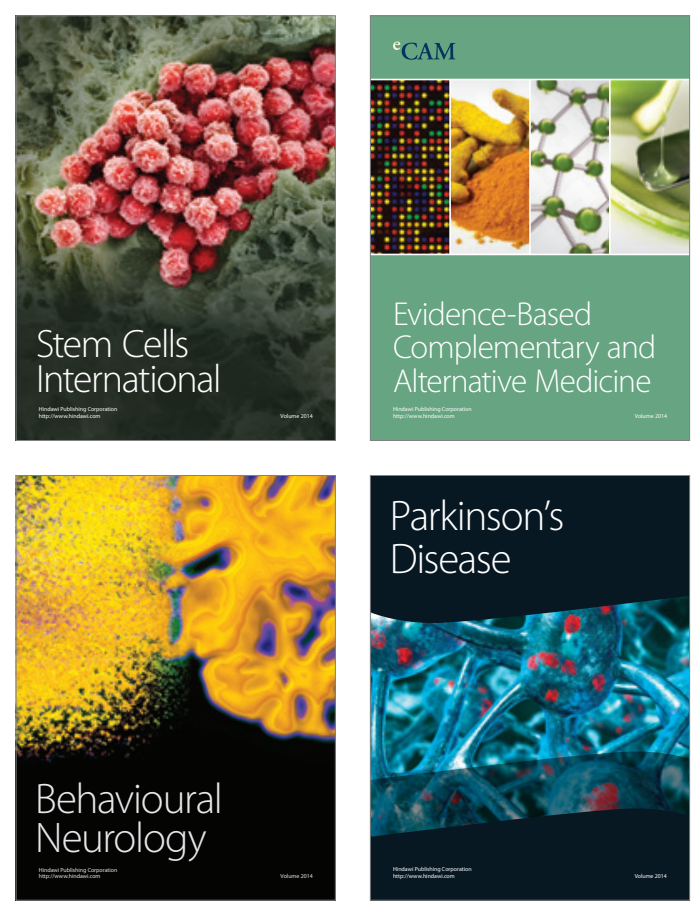

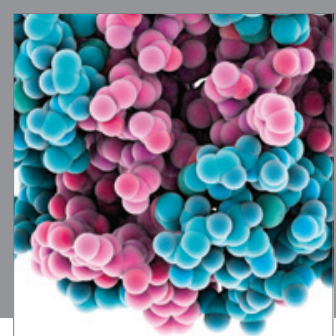

Journal of
Diabetes Research

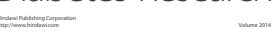

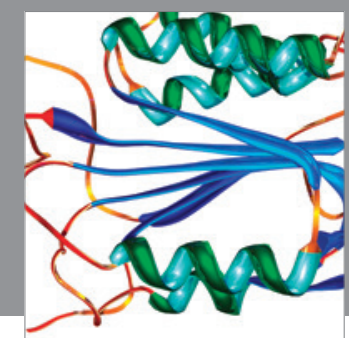

Disease Markers
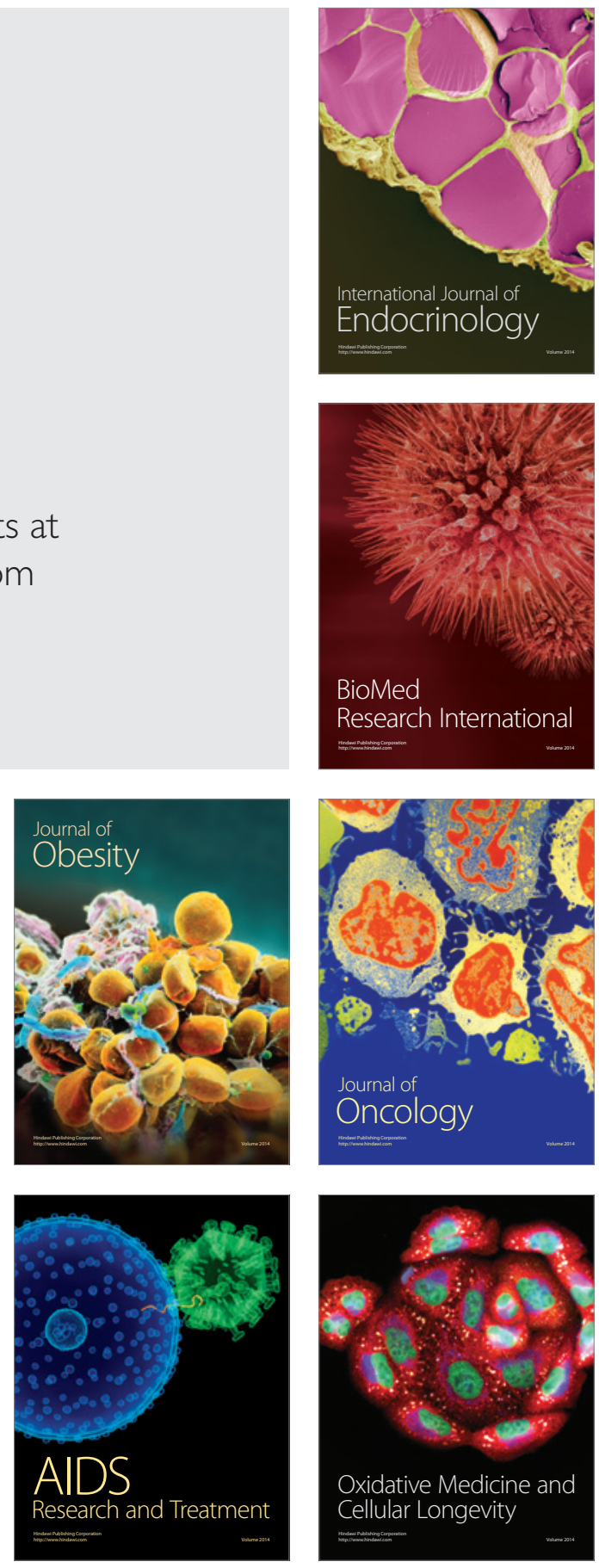